\title{
Design como processo complexo: uma reflexão sobre potenciais relações entre acaso, Design e funções dos produtos
}

\author{
Design as a complex process: a reflection on potential \\ links between chance, Design and product functions
}

por Fernanda de Souza Quintão, Ricardo Triska e Richard Perassi

RESUMO

Na análise das formas de interação dos cidadãos com as metrópoles contemNo século passado, em um momento dominado pelo racionalismo, quando a forma dos produtos deveria seguir a sua função prática, tentou-se excluir o acaso do processo de Design. Este trabalho, resultado de uma pesquisa teórica no campo de Design, procura refletir acerca de potenciais relações entre acaso, Design e complexidade, mediadas pela questão da funcionalidade de produtos, interpretando Design como processo inserido no pensamento complexo de Edgar Morin. Para tanto, conceitua-se complexidade; apresenta-se a participação do acaso no processo criativo; destacam-se racionalidade e objetividade, presentes no funcionalismo; e apresenta-se 0 desdobramento das funções do produto. Por fim, discute-se de que maneira Design pode ser visto como processo complexo. Conclui-se que isso se dá quando o design, mesmo partindo de uma metodologia objetiva, reconhece o acaso como parte de seu processo; também a definição das funções estética e simbólica rompe com o reducionismo anterior, que via apenas a objetividade da função prática, e confirma a inserção do design na complexidade.

Palavras-chave acaso; funções do produto; design; complexidade; Edgard Morin

ABSTRACT

Last century, in a moment dominated by rationalism, when products form should follow its practical function, there was an attempt to exclude chance from Design process. This article results from a theoretical research at Design field and aims to reflect on potential links between chance, Design and complexity, mediated by the issue of products functionality, interpreting Design as a process inserted at Edgar Morin's complex thought. Therefore, we define complexity; present the role of chance at creative process; highlight rationality and objectivity from functionalism; and present the split of product functions. Finally, we discuss on how Design can be seen as complex process. We conclude that this occurs when design, even coming from an objective methodology, recognizes chance as part of its process; also the definition of both aesthetic and symbolic functions breaks with the previous reductionism, which considered just the practical function, and confirms the place of Design in complexity.

Keywords chance; products' functions; design; complexity; Edgar Morin 


\section{Introdução}

0 design, considerado a atividade de projetar produtos a serem produzidos em uma etapa posterior, surgiu na Inglaterra do século XVIII, num momento que foi marcado pela separação entre as etapas de concepção e de fabricação de objetos, anteriormente executadas pela mesma pessoa (BÜRDEK, 1999). Desde o início da Revolução Industrial, e durante um longo período da história do design, uma grande preocupação relacionada à fabricação dos bens materiais era a padronização da produção em série, em que os objetos finais, resultantes do processo industrial, deveriam ser idênticos entre si (FORTY, 2000).

As primeiras empresas a apostarem na produção em série possuíam showrooms, onde eram exibidas amostras dos produtos, mas não havia estoque para entrega imediata; posteriormente, as vendas eram feitas por viajantes que visitavam as cidades com amostras e catálogos ilustrados com imagens dos produtos, mas também nesse caso não havia produtos para pronta entrega: os pedidos dos clientes eram enviados às fábricas, onde os objetos eram produzidos e, então, enviados ao cliente (FORTY, 2000). Esse modelo, em que o cliente tinha um primeiro contato com o produto (ou sua imagem) para então encomendá-lo e aguardar sua entrega, exigia que a fabricação resultasse em objetos que fossem idênticos entre si, garantindo que 0 cliente recebesse um exemplar exatamente igual ao que havia visto na amostra ou na imagem do catálogo. Portanto, os trabalhadores responsáveis pela fabricação não tinham mais a liberdade de permitir a presença de variações durante a etapa de produção (FORTY, 2000) e procurava-se eliminar o acaso do processo de fabricação.

Durante um longo período na história do design, em que o grande objetivo era produção em massa, para quantidades cada vez maiores de consumidores, procurou-se suprimir do produto final, resultado do processo industrial de fabricação de objetos, o que era aleatório e inesperado. Mas em tempos mais recentes, com o estabelecimento da produção para nichos, e não apenas para a massa consumidora, percebe-se, em grupos específicos, uma retomada da aceitação do acaso no produto final, que passa a ser visto como objeto único. 0 design, nesse contexto, se aproxima do modo artístico e/ou artesanal de produção.

No entanto, seja na produção em massa ou para nichos, o acaso pode fazer parte das etapas que compõem o design (ou projeto) dos produtos, na fase anterior à produção propriamente dita. Mas, mesmo na etapa do projeto, o aleatório nem sempre foi bem aceito, por ser o elemento que suspende a objetividade no design, eliminando o determinismo por vezes presente no discurso do projeto. Em um momento dominado pelo racionalismo, quando a forma dos produtos deveria seguir a sua função estritamente prática, tentou-se excluir o acaso do processo do design, uma vez que se buscava uma maneira científica (e, portanto, objetiva) de alcançar as soluções procuradas. Mas a partir do instante em que, além da função prática, são definidas as funções comunicativas (estética e simbólica) dos produtos, o acaso é reincorporado ao design, que passa a comportar, além dos aspectos objetivos, 
também os subjetivos. Nesse contexto, ao se considerar a existência do elemento aleatório no processo de concepção de produtos, o design pode ser interpretado a partir da complexidade do pensador francês Edgar Morin.

0 objetivo que motiva este artigo é identificar as potenciais relações existentes entre casualidade, Design e complexidade, mediadas pela questão da funcionalidade em Design. Considera-se que algumas ocorrências casuais, aqui denominadas de "acaso", são aceitas e, posteriormente, incorporadas ao projeto de Design. Isso ocorre porque tal eventualidade é percebida como algo que atende às finalidades do projeto, sejam essas práticas, estéticas, ou simbólicas. Considera-se, ainda, que a divisão da finalidade do projeto em funções categorizadas como práticas, estéticas e simbólicas acrescenta complexidade à questão da funcionalidade do produto de Design, inserindo o tema no contexto epistemológico da complexidade indicada nos princípios apresentados por Edgar Morin (2003).

Para isso, inicialmente conceitua-se o pensamento complexo formulado por Edgar Morin, a partir de seus sete princípios-guia. Em um segundo momento, apresenta-se de que maneira 0 acaso participa do processo de criação, presente durante o desenvolvimento de um projeto. Em seguida, destaca-se o fator racional do funcionalismo no design, quando os aspectos subjetivos eram descartados do projeto, em favor do atendimento da função prática do produto final, e apresenta-se o desdobramento das funções do produto, a partir do reconhecimento dos seus aspectos comunicativos. Por fim, partindo dos conceitos do acaso e das funções do produto, discute-se de que maneira o design pode ser visto como um processo complexo.

Trata-se de uma pesquisa teórica que, a partir da reflexão proposta, visa à confrontação de conceitos para compreender características do processo de Design (SOUSA, 2012).

\section{Princípios do pensamento complexo de Edgar Morin}

Edgar Morin, antropólogo, sociólogo e filósofo francês nascido em 1921, é um pensador da complexidade na área das ciências humanas e sociais (MINAYO, 2011). Teoria da complexidade é, de acordo com Minayo (2011, p. 47), “um termo genérico para explicação convergente de vários movimentos epistemológicos da ciência contemporânea".

Para Morin (2003), são encontrados inúmeros elementos e premissas do pensamento complexo tanto na filosofia ocidental quanto na oriental, desde a relação dialógica identificada no yin-yang chinês.

Mas cronologicamente, a complexidade de Morin surgiu como consequência da Teoria Geral dos Sistemas, desenvolvida pelo biólogo austríaco Ludwig von Bertalanffy na década de 1930. Em seu trabalho, Bertalanffy discutia a substituição dos fundamentos mecanicista-cartesianos da ciência por uma visão holística (CAPRA, 2006). Assim, a partir do pressuposto de que um conjunto sistêmico representa mais que a soma 
de suas partes, Bertalanffy propunha a troca do pensamento analítico, em que um problema é decomposto em partes, pelo pensamento sistêmico-contextual, em que as relações entre as partes são mais importantes do que as partes em si.

Em sua obra, Morin também critica o caráter analítico do pensamento cartesiano: "a inteligência parcelada, compartimentalizada, mecanicista, disjuntiva, reducionista, destrói a complexidade do mundo em fragmentos distintos, fraciona os problemas, separa o que está unido, unidimensionaliza o multidimensional" (MORIN, 2003, p. 71). De acordo com Morin (2010), nos séculos XVI e XVII, período em que Descartes e Newton se destacaram na ciência, a ordem da natureza era explicada a partir da perfeição divina. No entanto, nos séculos XVIII e XIX, houve uma mudança na ciência que, com a eliminação do divino do seu discurso, encontrou na racionalidade um forte elemento de manutenção da ordem.

Morin (2010) desenvolve um "pentágono da racionalidade", em que apresenta as cinco principais características do racionalismo científico: a ordem, a objetividade, 0 determinismo, a causalidade e o controle. Nesse contexto, a desordem é o ruído que traz a angústia da incerteza diante do que não é controlável e 0 acaso vai contra a coerência e a causalidade, desafiando o pentágono da racionalidade.

Segundo 0 autor, até meados do século XX, a maior parte das ciências tinha o determinismo como principal conceito, ou seja, "a ocultação do acaso, do novo, das invenções, e a aplicação da lógica mecânica da máquina artificial aos problemas vivos, humanos e sociais" (MORIN, 2003, p. 69). A desordem foi recusada como uma subjetividade ignorante, como debilidade, incapacidade de se chegar à razão científica.

Assim, Morin (2003) apresenta o pensamento complexo como um pensamento que tem o propósito de, ao mesmo tempo, distinguir e reunir, no sentido de contextualizar e globalizar. 0 pensamento simplificador, ao contrário, separa o que está ligado e opera a redução, ao unificar o que é diverso (MORIN, 2011).

0 pensamento complexo é apresentado em sete princípios-guia que são complementares e interdependentes (MORIN, 2003). A seguir é apresentada uma interpretação desses princípios:

1. Princípio sistêmico ou organizacional, que se opõe ao reducionismo e procura unir o conhecimento das partes com o conhecimento do todo. A organização do todo produz as emergências, qualidades que só surgem a partir da interação entre as partes. Mas, ao mesmo tempo, o todo também é menos que a soma das partes, pois muitas de suas qualidades individuais são inibidas pela organização do conjunto;

2. Princípio hologramático, que evidencia o aparente paradoxo dos sistemas complexos, nos quais a parte se encontra no todo, assim como o todo está inscrito na parte. Um exemplo é a célula, que faz parte de um organismo e, ao mesmo tempo, contém, em seu material genético, as informações sobre todo o organismo;

3. Princípio do ciclo retroativo, que permite o conhecimento dos processos autorreguladores, rompendo com o princípio da causalidade linear, a partir da percepção 
de que a causa age sobre o efeito, assim como o efeito age sobre a causa;

4. Princípio do ciclo recorrente, que substitui a noção de regulação pelas de autoprodução e auto-organização. Nesse ciclo, os próprios produtos e suas consequências são produtores e originadores daquilo que produzem;

5. Princípio de auto-ecoorganização (autonomia/dependência), que diz respeito à relação entre a autonomia e a dependência nos seres vivos. Ao mesmo tempo em que eles têm a autonomia de se organizar e se autoproduzir, eles dependem do meio externo para retirar a energia, a informação e a organização do seu ambiente: por causa da autonomia, eles são dependentes e por causa da dependência, são autônomos;

6. Princípio dialógico, que une dois princípios, ou noções, aparentemente contraditórios e excludentes, mas que são indissociáveis. Como exemplo, o autor apresenta os conceitos de ordem, desordem e organização, que estão associados desde o início do universo. A partir do princípio dialógico, é possível aceitar essa associação de noções contraditórias para conceber um fenômeno complexo;

7. Princípio da reintrodução do conhecido em todo o conhecimento, que restaura um tema central, segundo o qual todo o conhecimento é uma reconstrução por uma inteligência em uma cultura e em um tempo determinados.

Morin procura esclarecer que não se deve confundir complexidade com completude, uma vez que "o problema da complexidade não é o da completude, mas o da incompletude do conhecimento" (MORIN, 2010, p. 176). 0 pensamento complexo quer dar conta daquilo de que os pensamentos simplificadores se desfizeram; ele luta não contra a incompletude, mas contra a mutilação, e tende para o conhecimento multidimensional não a partir de todas as informações sobre um fenômeno específico, mas a partir do respeito às várias dimensões desse fenômeno. 0 pensamento complexo, ao aspirar à multidimensionalidade, comporta em seu interior um princípio de incompletude e de incerteza (MORIN, 2010). Ele renuncia ao mito da elucidação total do universo, e enxerga o conhecimento como um diálogo com esse universo: “0 objeto do conhecimento não é o mundo, mas a comunidade nós-mundo, porque o nosso mundo faz parte da nossa visão do mundo, que faz parte do nosso mundo" (MORIN, 2010, p. 205).

Nesse sentido, na complexidade de Morin o conhecimento deve negociar com a incerteza, uma vez que o objetivo do conhecimento é dialogar com o mundo, e não descobrir seu segredo ou equação-chave. Mas também não se trata de substituir a certeza pela incerteza, a separação pela inseparabilidade, a lógica pela transgressão: “o procedimento consiste, ao contrário, em se fazer uma ida e vinda incessante entre certezas e incertezas, entre o elementar e o global, entre o separável e o inseparável" (MORIN, 2003, p. 75). A complexidade é, além de pensar conjuntamente o uno e o múltiplo, fazê-lo com o certo e o incerto, com o lógico e o contraditório (MORIN, 2010). Nas palavras do autor:

0 pensamento complexo é, portanto, essencialmente, o pensamento que lida com a incerteza e que é capaz de conceber a organização. Trata- 
-se de um pensamento capaz de reunir, contextualizar, globalizar, mas ao mesmo tempo de reconhecer o singular, o individual, o concreto. 0 pensamento complexo não se reduz nem à ciência, nem à filosofia, mas permite a comunicação mútua, fazendo o intercâmbio entre uma e outra. (MORIN, 2003, p. 77)

\section{0 acaso no processo de criação}

A natureza do acaso é discutida desde tempos antigos. De acordo com Abbagnano (2007), no século IV AC, Aristóteles atribui o acaso ao imprevisível, ou seja, àquilo que acontece fora do necessário e do uniforme, mas que possui uma finalidade definida. Por outro lado, no século III AC, os estoicos relacionavam o acaso ao erro ou à ilusão, uma vez que, para eles, os acontecimentos que ocorriam no mundo estavam submetidos a uma causa ou necessidade racional. Os estoicos, portanto, não reconheciam a existência de acontecimentos acidentais ou fortuitos; considerar o acaso era um erro, um desconhecimento de uma razão superior (ABBAGNANO, 2007). Posteriormente, no século XVIII, Kant também negava a existência do acaso, tendo afirmado na Crítica da Razão Pura que a proposição 'nada ocorre por acaso' (in mundo nun datur casus) era uma lei a priori da natureza (ABBAGNANO, 2007, p. 12).

Contrapondo-se ao determinismo, a discussão sobre o acaso também está presente em aspectos relacionados tanto à religião - como a questão do livre-arbítrio - quanto à ciência - principalmente nas áreas da probabilidade, da entropia e da teoria quântica (RUELLE, 1993).

No entanto, para fins deste artigo, o acaso não será abordado do ponto de vista religioso, nem do científico. Assumimos o acaso como uma entidade existente e o consideraremos em sua relação com o processo criativo.

0 processo de criação é composto pelas etapas de inspiração inicial, preparação, incubação, iluminação e verificação (BAXTER, 2000). Um resultado considerado criativo para um determinado problema é alcançado a partir de novas formas de relacionar ideias já existentes. Para isso, é necessário que o indivíduo esteja envolvido com uma questão que deva ser solucionada.

Baxter (2000) apresenta 0 já bastante citado caso do eureca de Arquimedes: um dos principais cientistas da antiguidade clássica, Arquimedes se encontrava, por volta do ano 230 a.C., encarregado de verificar se a coroa de Heiro, governador de Siracusa, era mesmo feita de ouro puro ou se havia sido adulterada com prata. Como naquela época o peso específico do ouro já era conhecido, Arquimedes precisava descobrir o volume da coroa para, assim, confirmar, ou não, a adulteração. Entretanto, como ele não poderia fundir a coroa para verificar seu volume, a medida deveria ser feita de outra maneira. Envolvido com essa questão, um dia, Arquimedes, ao entrar na banheira para tomar um banho, prestou atenção ao fato 
de seu corpo ter deslocado a água, elevando o nível do líquido na banheira. Ele, então, percebeu que a resposta para o problema estava bem à sua frente: para saber o volume da coroa, bastaria mergulhá-la em um recipiente com água e medir o volume de líquido deslocado. A fábula diz que, nesse momento, Arquimedes saiu nu pelas ruas, gritando "Eureca! Eureca!" ("Achei! Achei!"). Fato ou lenda, essa história é um bom exemplo de como o envolvimento pessoal com um problema específico e a necessidade de encontrar uma solução fazem com que um fato corriqueiro se transforme em um acaso significativo.

0 acaso é definido em Weiszflog (2007) como um acontecimento incerto, imprevisível, que não possui o grau de determinação normal que o homem poderia prever. ostrower (1990) ressalta que para que seja considerado um acaso, o fenômeno deve ser percebido pelo observador, já que a todo o momento ocorrem eventos aparentemente desconexos e fora do controle. Apenas aqueles que são registrados podem se tornar acasos; todo o resto é casualidade.

Isso implica a questão da seleção ou do reconhecimento que leva a esse registro (ou percepção) de eventos específicos, tornando-os acasos significativos. Para 0strower (1990), apesar de não poderem ser planejados ou controlados, os acasos acontecem porque, de alguma maneira, já são esperados, mesmo que essa espera se dê inconscientemente. A partir do momento em que o indivíduo se encontra receptivo à ocorrência do acaso, ele se torna atento aos acontecimentos ou fenômenos ao seu redor.

Os acasos colaboram com a construção de conexões onde elas aparentemente não existem: "Sua descoberta pode nos surpreender num primeiro instante, mas ela assume imediatamente a forma de uma nova lógica, de um novo modo de se entender as coisas" (OSTROWER, 1990, p. 7). São os momentos chamados "inspiradores", quando "se interligam sugestões, proposições, avaliações, emoções e tudo se reformula" (OSTROWER, 1990, p. 19). No entanto, a inspiração não é a única responsável pelo resultado final alcançado, principalmente no caso do design, em que geralmente há uma metodologia orientando o projeto; o papel da inspiração é indicar um caminho possível. A afirmação diz respeito especificamente à criação artística, abordada na obra de 0strower (1990), mas pode ser transposta também para outras áreas em que o processo criativo está envolvido com a solução de um problema, como no mencionado caso de Arquimedes e também no processo de Design.

Considerando-se que o projeto de um produto envolve o processo de criação, e que eventos imprevisiveis ocorrem a todo o momento, pode-se afirmar que 0 acaso faz parte também do processo de Design e que ignorar tal fato é ignorar um componente importante desse processo. Um designer, durante a concepção de um novo objeto, pode se deparar com acontecimentos que parecem trazer um novo conhecimento para o projeto.

Munari (1998), discorrendo sobre metodologia de projeto, afirma que os métodos não são absolutos ou definitivos e podem ser alterados caso o designer identifique elementos que melhorem o processo. Para o autor, "as regras do método não 
bloqueiam a personalidade do projetista; ao contrário, estimulam-no a descobrir coisas que, eventualmente, poderão ser úteis também aos outros" (MUNARI, 1998).

De qualquer maneira, é importante reforçar que o acaso não surge do nada: ele só ocorre em função do contexto do projeto em andamento, e de uma expectativa, consciente ou não, do próprio designer.

\section{Funcionalismo: a expressão do racionalismo no design}

Nem sempre 0 acaso foi considerado parte integrante, e importante, do processo de Design. 0 funcionalismo, resultante do Movimento Moderno que se iniciou no período após a Primeira Guerra Mundial, pregava a máxima "a forma segue a função", cuja autoria é atribuída ao arquiteto norte-americano Louis Sullivan (18561934) (BÜRDEK, 1999). Nesse enfoque, um problema de Design estava sempre condicionado exclusivamente à função exercida pelo produto em foco e, portanto, sua resolução se dava a partir da utilização do pensamento racional, científico e objetivo. Dessa maneira, eram eliminados os aspectos subjetivos, como a indeterminação do acaso, na criação de uma solução.

A Alemanha exerceu um papel fundamental para o fortalecimento do funcionalismo e sua estética racionalista. A derrota ocorrida na Primeira Guerra Mundial fez com que o país se encontrasse, à época, em uma condição política, social e econômica trágica, dilacerada por conflitos de classe (ARGAN, 1992). Nesse contexto, "é necessário opor a este irracionalismo político, que leva à exasperação das contradições sociais e à violência, um racionalismo crítico, que dialetize todos os contrastes e resolva-os pelo fio da lógica e não pelo da espada" (ARGAN, 1992, p. 269). Walter Gropius (18831969), arquiteto alemão ligado à Werkbund, e defensor da estandardização da produção industrial (NIEMEYER, 2007), em 1919, funda a Staatliches Bauhaus in Weimar. Sobre a ideologia que orientava da escola, Argan (1992) escreve:

"A racionalidade deve enquadrar as grandes e pequenas ações da vida: racionais devem ser a cidade em que se vive, a casa em que se mora, a mobília e os utensílios que se empregam, a roupa que se veste. Apenas um método de construção ou, mais precisamente, de projeto deve determinar a forma racional de tudo o que serve à vida e a condiciona; como tudo é ou será produzido pela indústria, tudo se reduz a projetar para a indústria: o plano urbanístico de uma grande cidade é o desenho industrial, da mesma forma que o projeto de uma colher" (ARGAN, 1992, p. 270).

A Bauhaus foi se expandindo, mas questões políticas fizeram com que a escola sofresse críticas, que culminaram com sua extinção em 1933, quando foi invadida pela polícia nazista (NIEMEYER, 2007). De acordo com Niemeyer (2007), a maioria dos ex-professores e diretores se mudou para os Estados Unidos, onde fundaram 
novos núcleos de ensino e deram continuidade ao lema "a forma segue a função". Posteriormente, em 1951, foi fundada também na Alemanha outra escola de grande importância no contexto do design funcionalista: a Hochschule für Gestaltung, ou Escola Superior de Design de Ulm, considerada a instituição de Design mais importante criada após a Segunda Guerra Mundial (BÜRDEK, 1999). A escola foi dirigida, no início, por Max Bill, ex-aluno da Bauhaus e grande defensor do racionalismo no design. Bill (1908-1994), arquiteto e designer suíço, defendia o formalismo geométrico típico da Bauhaus e acreditava que produtos baseados em leis matemáticas possuíam pureza estética e, assim, eram mais atrativos (FIELL; FIELL, 2000). Após a saída de Max Bill da direção da escola, Tomás Maldonado, teórico argentino de Design, assume seu lugar e as disciplinas científicas e técnicas ganham maior importância, dominadas pelo pensamento cartesiano (BÜRDEK, 1999). Maldonado propunha uma nova definição do design industrial, o 'operacionalismo científico', que defendia a padronização de objetos, o que resultou no desenvolvimento de uma estética racional (NIEMEYER, 2007). De acordo com Bürdek (1999), era exigido dos alunos que os processos de Design fossem elaborados de maneira consciente e controlada.

0 funcionalismo se tornou uma diretriz do design na Alemanha 0cidental e marcou o design industrial no mundo durante várias décadas, quando a produção em série encontrou nesse enfoque um instrumento para a padronização e a racionalização (BÜRDEK, 1999). Mas principalmente a partir da década de 1980, começaram a surgir críticas ao seu racionalismo excessivo e à falta de flexibilidade.

Um grande crítico do Movimento Moderno e do funcionalismo foi Peter Blake (19202006), arquiteto e crítico nascido na Alemanha e naturalizado norte-americano. Em seu livro Form Follows Fiasco (a forma segue o fiasco), Blake analisa os principais mitos da arquitetura moderna, como o culto à máxima "a forma segue a função" e à industrialização, a busca pela pureza e a padronização, que não leva em conta particularidades na solução de problemas (PORTOGHESI, 1982). Um dos mitos analisados é o design e Blake critica móveis e objetos projetados por Le Corbusier, Mies van der Rohe e Marcel Breuer, que, com suas formas quadradas, em nada atendiam às exigências do movimento do corpo:

"Acomodar ou 'resolver os problemas' era o nome do seu jogo, é bem verdade. Mas o problema que o Movimento Moderno queria, de facto, resolver, a julgar pelas suas performances até a data, é a fastidiosa anatomia da raça humana: de facto, nada está em condições de funcionar - à maneira da Bauhaus - até que os homens não sejam reprojectados em forma de cubos e as mulheres em formas de esferas" (BLAKE apud: PORTOGHESI, 1982, p. 41).

No contexto do funcionalismo, os designers deveriam dar respostas com o grau máximo de funcionalidade. No entanto, o conceito de função utilizado nesse enfoque, de acordo com Bürdek (1999), era muito limitado, pois apenas a função prática (ou técnica) era considerada: "Ia dimensión de las funciones de los signos o de las funciones comunicativas del producto continuaron siendo tabú" ("as di- 
mensões das funções dos signos ou das funções comunicativas do produto continuaram sendo tabu") (BÜRDEK, 1999, p. 55).

Segundo Bürdek (1999), essa limitação na concepção da função se apoiou em um mau entendimento da hipótese de Sullivan, já que o arquiteto se referia também aos aspectos semióticos do produto. Para Sullivan, não se tratava apenas de satisfazer as necessidades da finalidade dos produtos, mas também da possibilidade de reconhecimento da vida em sua expressão, da forma tanto da função física como da espiritual (BÜRDEK, 1999).

A inserção da semiótica, ou teoria dos signos, no cenário do design desde a década de 1960 (BÜRDEK, 1999) colaborou com o debate sobre a questão das funções dos produtos. Ao assumir os objetos como signos dotados de aspectos comunicativos, verificou-se que as funções do produto se definem no uso deste por parte do usuário. A partir do estudo do linguista checo Jan Mukařovský (1891-1975) na área da semiótica e da estética, foram inferidas funções dos produtos, separadas entre práticas e sinalizadoras (BÜRDEK, 1999). Posteriormente, as funções específicas da área do design foram mais bem diferenciadas, o que conduziu a um esquema conceitual que constitui o núcleo da teoria da linguagem comunicativa do produto (BÜRDEK, 1999, p. 179).

\section{As funções do produto do design}

A tarefa do designer é traduzir em signos as diferentes funções de um produto, de maneira que eles possam ser compreendidos pelo usuário (BÜRDEK, 1999). Löbach (2001) apresenta a classificação das funções de um produto industrial (ou objeto de Design) a partir do uso pelo comprador (ou usuário) proposta por J. Gross, que inclui as funções práticas, estéticas e simbólicas. Bürdek (1999) também considera a função prática, mas se refere a ela principalmente a partir das funções indicativas, que, assim como as funções estético-formais e as funções simbólicas, são consideradas funções sinalizadoras.

\section{Funções prática e indicativa}

De acordo com Löbach, "são funções práticas de produtos todos os aspectos fisiológicos do uso" (LÖBACH, 2001, p. 58). 0 autor cita como exemplo a cadeira, que, por meio das suas funções práticas, satisfaz as necessidades fisiológicas do usuário, facilitando que o corpo assuma uma posição que previne o cansaço físico.

Löbach destaca a função prática como sendo o principal objetivo do desenvolvimento de produtos: "as funções práticas dos produtos preenchem as condições fundamentais para a sobrevivência do homem e mantêm a sua saúde física" (LÖBACH, 2001, p. 58).

Bürdek (1999), conforme mencionado, aborda a função prática a partir da função indicativa, responsável pela comunicação dos aspectos técnicos, que explicam o 
uso do produto. Hans-Ullirich Bitsch, citado por Bürdek (1999), afirma que o uso ao qual um produto é destinado deve estar legível nele mesmo. São alguns exemplos de sinais indicativos, de acordo com o autor: delimitação; contraste; estruturas superficiais; formação de grupos; contraste de cores; orientação; solidez; estabilidade; versatilidade e ajustabilidade; manejo; precisão; e relação com o corpo humano.

\section{Função estética}

A função estética ou, para Bürdek (1999), função estético-formal, está relacionada aos aspectos independentes do significado do conteúdo do objeto. Löbach (2001) complementa a opinião de Bürdek. Para ele, a função estética é a relação entre produto e usuário no que diz respeito aos processos sensoriais: "é um aspecto psicológico da percepção sensorial durante seu uso" (LÖBACH, 2001, p. 60). 0 autor coloca a função estética como tarefa principal do designer industrial. Para ele, configurar um produto industrial é dar a ele funções estéticas, atendendo à percepção multissensorial do usuário.

Essa função é imposta à nossa percepção, se une às outras e as supera (LÖBACH, 2001, p. 63), atraindo o interesse dos usuários por determinado produto.

\section{Função simbólica}

Löbach define a função simbólica como sendo "determinada por aspectos espirituais, psíquicos e sociais do uso" (LÖBACH, 2001, p. 64). Ela deriva da função estética, a partir da utilização de elementos como cor, forma e tratamento de superfície, e possibilita, por exemplo, que sejam feitas associações com experiências passadas. De acordo com o autor, "a função simbólica só é efetiva se for baseada na aparência percebida sensorialmente e na capacidade de associação de ideias" (LÖBACH, 2001, p. 65).

Bürdek (1999) considera a função simbólica como a mais complexa das funções comunicativas do produto, já que ela não é composta por princípios, como a função estética, nem pode ser testada empiricamente, como a função indicativa ou prática: os significados simbólicos só podem ser extraídos do contexto sociocultural em questão (BÜRDEK, 1999, p. 224). Do ponto de vista da teoria da comunicação do produto, os contextos sociais, socioeconômicos e culturais do design se refletem nas funções simbólicas.

De acordo com Bürdek (1999), o processo de autodefinição do indivíduo começou na Europa do século XVIII, mas apenas na década de 1960 se transformou em um importante fenômeno social. 0 estabelecimento de uma sociedade hiperconsumista levou a indústria a investir na diferenciação dos objetos como forma de incentivar as vendas, constituindo os chamados "estilos de vida" e, consequentemente, elevando a importância dos aspectos simbólicos para o desenvolvimento de novos produtos. 


\section{Design como processo complexo}

Considerando-se que "a complexidade num certo sentido sempre tem relação com o acaso" (MORIN, 2011, p. 35) e que o design depende do processo criativo de um ou mais indivíduos, processo esse que conta com a presença constante do elemento 'acaso', observa-se que o processo de Design pode ser inserido na complexidade descrita nos sete princípios-guia propostos por Morin (2003).

0 acaso é um elemento que vai contra o pentágono da racionalidade apresentado por Morin (2010) e desestabiliza seus princípios de ordem, objetividade, determinismo, causalidade e controle. A inserção do design na complexidade ocorre a partir do momento em que, considerando que o processo de Design se dá a partir de uma metodologia que é objetiva e racional, o acaso é reconhecido como parte integrante desse processo.

0 método e o acaso se alternam e se complementam durante a atividade projetual: o designer, enquanto está envolvido com um projeto, apesar de geralmente obedecer a uma metodologia específica, por vários momentos se depara com a presença do aleatório ou do desconhecido, que pode contribuir de forma positiva para o desenvolvimento e a solução do projeto.

Ao associar o que é certo (o método, o aspecto racional) e o que é incerto (o acaso, 0 aleatório), o design promove as idas e vindas entre certezas e incertezas, citadas por Morin (2003) e mencionadas anteriormente nesse artigo. Nesse sentido, também se percebe no design o princípio dialógico da complexidade, em que conceitos aparentemente contraditórios e excludentes, no caso, aleatoriedade e racionalidade, são associados em um fenômeno.

Assim, não é o caso de negar o aspecto racional e objetivo do design, mas de não considerá-lo composto e orientado exclusivamente por esse caráter racional, como o Funcionalismo, a partir de uma distorção da hipótese de Sullivan, pretendeu fazer no século passado.

Sullivan, conforme Bürdek (1999), não se referia exclusivamente à função prática ao afirmar que "a forma segue a função", mas também a aspectos semióticos. Nesse contexto, 0 arquiteto pode ser interpretado a partir da complexidade, uma vez que considerava a função como sendo composta por elementos aparentemente sem relação. Posteriormente, o funcionalismo procurou simplificar a hipótese de Sullivan, em uma tentativa de eliminação da complexidade do seu discurso, 0 que conduziu o design a uma visão simplificada das funções do produto e, consequentemente, de si mesmo.

Com o surgimento de críticas contra o funcionalismo, principalmente a partir da década de 1980, verificou-se a necessidade de somar às funções práticas do produto os aspectos comunicativos. A definição das funções estética e simbólica rompe com o reducionismo anterior, que via apenas a objetividade da função prática, e confirma a inserção do design no âmbito da complexidade. 
Outro aspecto importante relacionado à inclusão desses fatores comunicativos na categorização das funções do produto é o fato de que eles permitem a reincorporação do acaso no projeto, uma vez que esse pode vir a enriquecer o cumprimento dos objetivos iniciais do projeto. No período do funcionalismo, quando apenas questões práticas e objetivas eram levadas em conta, o acaso não tinha tanto espaço para atuar. As funções estética e simbólica ampliam a possibilidade de aplicação do acaso no processo de Design.

Assim, ao associar a racionalidade com a subjetividade, o método com 0 acaso, respeitando a sua própria multidimensionalidade, o design vai além do pensamento simplificador e se firma como um processo epistemologicamente complexo.

\section{Considerações finais}

A proposta deste artigo foi promover uma reflexão acerca das relações entre acaso e Design, a partir da questão das funções dos produtos, em uma interpretação do design como processo inserido na complexidade definida por Morin (2003).

Para isso, foram apresentados os princípios-guia do pensamento complexo, definidos por Morin (2003), verificou-se a maneira como 0 acaso age no processo de criação e apresentou-se a redução provocada pelo funcionalismo no design, assim como a reintrodução da complexidade a partir da definição das funções estética e simbólica.

Considera-se de grande importância o reconhecimento do design como processo complexo, sujeito a aspectos tanto racionais e objetivos quanto aleatórios e subjetivos. A simplificação do design ao racionalismo o reduz a uma técnica, com regras e métodos específicos adotados para a concepção de um produto final. Ao levar em consideração a existência do acaso, elemento incerto e aparentemente aleatório, no processo de projetação, o design se firma como um processo rico e dotado de múltiplas dimensões. 


\section{Referências}

> ABBAGNANO, Nicola. Dicionário da Filosofia. São Paulo: Martins Fontes, 2007.

> ACASO. In: WEISZFLOG, Walter (Ed.). Michaelis: Moderno Dicionário da Língua Portuguesa.São Paulo: Melhoramentos, 2007. Disponível em: 〈http:// michaelis.uol.com.br/moderno/portugues/index.php?lingua=portuguesportuguesctpalavra=acaso> Acesso em: 07 jun. 2012.

$>$ ARGAN, Giulio Carlo. Arte moderna: do iluminismo aos movimentos contemporâneos. São Paulo: Companhia das Letras, 1992.

> BAXTER, Mike R. Projeto de produto: guia prático para o design de novos produtos. 2ร̌ ed. São Paulo: Blucher, 2000.

> BÜRDEK, Bernhard E. Diseño: historia, teoría y práctica del diseño industrial. 2š ed. Barcelona: Gustavo Gilli, 1999.

> CAPRA, Fritjof. A teia da vida: uma nova compreensão científica dos sistemas vivos. 10Š reimpressão da 1Š ed. São Paulo: Cultrix, 2006.

> FIELL, Charlotte; FIELL, Peter. Design do Século XX. Colônia: Taschen, 2000.

> FORTY, Adrian. Objects of Desire: design and society since 1750. Londres: Thames it Hudson, 2000.

> LÖBACH, Bernd. Design industrial: bases para a configuração dos produtos industriais. São Paulo: Edgard Blücher, 2001.

> MINAYO, Maria Cecília de S. Da inteligência parcial ao pensamento complexo: desafios da ciência e da sociedade contemporânea.In: Política đa Sociedade, Florianópolis, v. 10, n. 19, p. 41-56, out. 2011. Disponível em: 〈http://www.periodicos. ufsc.br/index.php/politica/article/view/2175-7984.2011V10n19p41/19592> Acesso em: 09 jun. 2012.

> MORIN, Edgar. A necessidade de um pensamento complexo. In: MENDES, Cândido (Org.); LARRETA, Enrique (Ed.). Representação e complexidade. Rio de Janeiro: Garamond, 2003, p. 69-78. Disponível em: <http://unesdoc.unesco.org/ images/0013/001317/131796por.pdf> Acesso em: 09 jun. 2012. Ciência com consciência. 14Š ed. Rio de Janeiro: Bertrand Brasil, 2010.

$>$ Introdução ao pensamento complexo. 4š ed. Porto Alegre: Sulina, 2011.

> MUNARI, Bruno. Das coisas nascem coisas. São Paulo: Martins Fontes, 1998.

> NIEMEYER, Lucy. Design no Brasil: origens e instalação. Rio de Janeiro: 2AB, 2007.

> OSTROWER, Fayga. Acasos e criação artística. Rio de Janeiro: Campus, 1990.

> PORTOGHESI, Paolo. Depois da arquitectura moderna. Lisboa: Martins Fontes, 1982.

> RUELLE, David. Acaso e caos. São Paulo: Editora da Universidade Estadual Paulista, 1993. 
Design como processo complexo: uma reflexão sobre potenciais relações entre acaso, Design e funções dos produtos

> SOUSA, Richard P. L. de. Fundamentos da Pesquisa. EGR8005000-42000002ME (20121) Fundamentos da Pesquisa. [online via AVA interno], Universidade Federal de Santa Catarina, 2012. Disponível em: 〈http://moodle.ufsc.br/mod/resource/ view.php?id=241111> Acesso em: 13 jun 2012.

Fernanda de Souza Quintão, UFSC

fernandaq@gmail.com

Ricardo Triska, UFSC

ricardo.triska@gmail.com

Richard Perassi Luiz de Sousa, UFSC

richard.perassi@uol.com.br 